very difficult working atmosphere. Repeated discussions about the value of psychiatry of mental handicap as a subspeciality also created uncertainties among those working in community settings with people with mental handicap and about the value of my work as a psychiatrist.

\section{Comments}

Most publications of the Royal College of Psychiatrists have dealt with the changes in service provision for people with mental handicap rather than with the training of staff (Royal College of Psychiatrists, 1978, 1980, 1983).

In 1980 the Mental Deficiency Section of the College complained about the state of the mental handicap services and noted a shortage of manpower and poor recruitment to the speciality resulting in a deteriorating service (Royal College of Psychiatrists, 1980). As one of then long-term solutions, they recommended that each trainee in general psychiatric training should complete six months in mental handicap as part of the rotational scheme. At this stage it seemed that the incorporation of a training post in the psychiatry of mental handicap should serve to attract trainees into this subspeciality rather than to give future adult general psychiatrists some experience in the psychiatry of mental handicap.

In 1985, the College published guidelines for registrar training in mental handicap (Royal College of Psychiatrists, 1985). In the introduction the College stated that in the future all psychiatrists, whatever their speciality, would be likely to encounter the mentally handicapped during the course of their professional life, and therefore recommended adequate exposure to the subject in vocational training programmes. The training recommendations were fairly detailed for the academic course, but remained rather vague when outlining clinical experience. It stated that the attachment should aim to provide experience in all aspects of care with the main emphasis on psychiatric aspects.

South West Thames and the St George's Hospital Medical School Rotational Training Scheme in Psychiatry provides registrars with a syllabus of the training experiences that are appropriate during a placement as registrar in the psychiatry of mental handicap. I feel that a placement in psychiatry of mental handicap is a valuable experience for trainees, whatever speciality they plan to enter. It may attract trainees to this subspeciality but this should not be the main object of such a placement. I have outlined above my experiences during the placement both in terms of personal and psychiatric experiences. If such a placement should become an integral part of training in general psychiatry, written guidance such as that provided by the St George's scheme would help to validate the experience.

\section{Acknowledgement}

I would like to thank Professor Sheila Hollins for her helpful comments and Drs D. Kohen and G. Matthews for encouragement and advice on the preparation of this paper.

\section{References}

Royal College of Psychiatrists (1978) Memorandum on mental handicap. Bulletin of the Royal College of Psychiatrists, 2, 56-61.

-(1980) Mental Deficiency Section. Bulletin of the Royal College of Psychiatrists, 4, 61 .

- (1983) Mental handicap services - the future. Bulletin of the Royal College of Psychiatrists, 7, 131-133.

- (1985) Registrar training in mental handicap. Bulletin of the Royal College of Psychiatrists, 9, 206.

\title{
Winter Quarterly Meeting 1993: tape recordings
}

The Programmes and Meetings Committee have taped the proceedings of the Winter Quarterly Meeting 1993. This Meeting consists of the Maudsley Bequest Lecture Series, which are overview presentations aimed primarily but not exclusively at the needs of trainees.

Individual copies of the tapes can be purchased from Deborah Hart, Public Education Officer, at the College at $£ 6.00$ a copy (each tape will include two lectures); a set of nine tapes of the whole meeting can be obtained for $\mathbf{\$ 4 0 . 0 0}$. These costs include postage and packing and cheques should be made payable to The Royal College of Psychiatrists. 